\title{
NEW ANTIBIOTICS SF2315A AND B PRODUCED BY AN EXCELLOSPORA SP.
}

\section{THE STRUCTURAL ELUCIDATION}

\author{
Toru Sasaki, Shuichi Gomi and Masaji Sezaki \\ Pharmaceutical Research Laboratories, Meiji Seika Kaisha, Ltd., \\ Morooka-cho, Kohoku-ku, Yokohama 222, Japan \\ Yasuo Takeuchi, Yoshio Kodama and Keni Kawamura \\ Pharmacology and Toxicology Laboratories, Meiji Seika Kaisha, Ltd., \\ Morooka-cho, Kohoku-ku, Yokohama 222, Japan \\ (Received for publication December 5, 1987)
}

\begin{abstract}
The structures of antibiotics SF2315A and $\mathrm{B}$ were determined to be $[4 \mathrm{a} R-(4 \mathrm{a} \beta, 12 \mathrm{~b} \beta)]$ or [4a $S$-(4a $\alpha, 12 b \alpha)$ - $4 \mathrm{a}, 5,6,12 \mathrm{~b}$-tetrahydro-4a,8-dihydroxy-3-methylbenz[a]anthracen-1,7,12(4H)trione and $[1 S-(1 \beta, 4 \mathrm{a} \beta, 6 \mathrm{a} \beta, 12 \beta, 12 \mathrm{a} \beta, 12 \mathrm{~b} \beta)]$ or $[1 R-(1 \alpha, 4 \mathrm{a} \alpha, 6 \mathrm{a} \alpha, 12 \alpha, 12 \mathrm{a} \alpha, 12 \mathrm{~b} \alpha)]-1,4,4 \mathrm{a}, 5,6,6 \mathrm{a}$,12a,12b-octahydro-1,4a,8,12-tetrahydoxy-3-methyl-6a,12a-epoxybenz[a]anthracen-7(12H)-one, respectively from their spectroscopic analyses and single crystal $X$-ray diffraction analyses.
\end{abstract}

Two new antibiotics SF2315A and B which are weakly active against Gram-positive bacteria have been isolated from the culture filtrate of Excellospora sp. SF2315 $5^{1)}$. Both antibiotics have the carbon skeletons of benz[a]anthracene. In this paper we report on the structural elucidation of these antibiotics based on spectral analyses and single crystal X-ray diffraction analyses.

Structure of Antibiotic SF2315A

The molecular formula of antibiotic SF2315A (I) was determined to be $\mathrm{C}_{18} \mathrm{H}_{18} \mathrm{O}_{5}$ from the elemental analysis, high resolution (HR)-MS ( $\mathrm{M}^{+} \mathrm{m} / \mathrm{z}$ calcd: 324.0997 , found: 324.1062 ), ${ }^{1} \mathrm{H}$ and ${ }^{13} \mathrm{CNMR}$ spectra (Tables 1 and 2).

The UV spectrum of $I$ in methanol exhibited maxima at 237, 269 and $419 \mathrm{~nm}$ which were shifted to 272 and $515 \mathrm{~nm}$ in basic methanol. The IR spectrum showed the absorption due to hydroxyl groups $\left(3400 \mathrm{~cm}^{-1}\right)$, an unsaturated ketone $\left(1690 \mathrm{~cm}^{-1}, \mathrm{sh}\right)$, a non-chelated quinone $\left(1660 \mathrm{~cm}^{-1}\right)$ and a chelated quinone carbonyl group $\left(1640 \mathrm{~cm}^{-1}\right)$. The above data together with an ABX spin system of aromatic proton signals at $\delta 7.33(9-\mathrm{H}), 7.56(11-\mathrm{H})$ and $7.74(10-\mathrm{H})$ and a hydrogen-bonded phenolic proton at $\delta 11.91(8-\mathrm{OH})$ in the ${ }^{1} \mathrm{H}$ NMR spectrum of $\mathbf{I}$ (Table 1) suggested the presence of a substituted 5-hydroxy-1,4-naphtoquinone (juglone) ${ }^{2)}$ moiety in $\mathbf{I}$.

The ${ }^{1} \mathrm{H}$ NMR spectrum of $I$ showed 16 proton signals (Table 1) and suggested the presence of

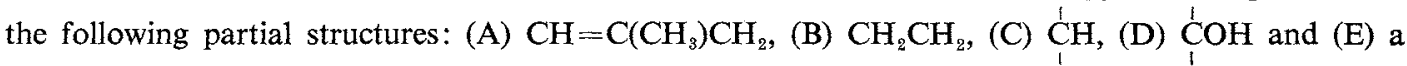
substituted juglone moiety.

The ${ }^{13} \mathrm{C}$ NMR spectrum of $I$ had 19 carbon signals, which could be attributed to two quinone carbonyls, one ketone carbonyl, ten aromatic or olefinic carbons, one quaternary carbon, one methine carbon, three methylene carbons and one methyl carbon (Table 2).

The chemical shifts in the ${ }^{13} \mathrm{C}$ NMR spectrum suggested that the ketone carbonyl carbon at $\delta 196.2$ (C-1) was an $\alpha, \beta$-unsaturated ketone carbonyl carbon. Therefore, the carbonyl carbon must be con- 
Table 1. ${ }^{1} \mathrm{H}$ NMR data of SF2315A (I) and SF2315B (II).

\begin{tabular}{|c|c|c|}
\hline Proton & SF2315A (I) & SF2315B (II) \\
\hline $1-\mathrm{H}$ & & $4.42 \mathrm{~m}$ \\
\hline $1-\mathrm{OH}$ & & $5.39 \mathrm{~d}(7.0)$ \\
\hline $2-\mathrm{H}$ & 5.78 br s & 5.34 br s \\
\hline $3-\mathrm{CH}_{3}$ & $1.99 \mathrm{~s}$ & $1.66 \mathrm{~s}$ \\
\hline $4-\mathrm{H}$ & $\begin{array}{l}2.91 \text { br d (18.4), } \\
2.46 \mathrm{~d}(18.4)\end{array}$ & $\begin{array}{l}2.14 \text { br d }(17.5) \\
1.94 \mathrm{~d}(17.5)\end{array}$ \\
\hline $4 a-O H$ & $5.24 \mathrm{~s}$ & $4.36 \mathrm{~s}$ \\
\hline $5-\mathrm{H}$ & $1.65 \mathrm{~m}$ & $1.56 \mathrm{~m}$ and $1.36 \mathrm{~m}$ \\
\hline $6-\mathrm{H}$ & $2.60 \mathrm{~m}$ & $\begin{array}{l}2.59 \mathrm{ddd}(3.1,7.8,15.6) \\
2.14 \mathrm{~m}\end{array}$ \\
\hline $8-\mathrm{OH}$ & $11.91 \mathrm{~s}$ & $11.33 \mathrm{~s}$ \\
\hline 9-H & 7.33 br d (8.6) & 6.87 br d $(7.8)$ \\
\hline $10-\mathrm{H}$ & $7.74 \mathrm{dd}(7.4,8.6)$ & $7.57 \mathrm{t}(7.8)$ \\
\hline $11-\mathrm{H}$ & 7.56 br d (7.4) & 7.18 br d $(7.8)$ \\
\hline $12-\mathrm{H}$ & & $5.29 \mathrm{~d}(7.0)$ \\
\hline $12-\mathrm{OH}$ & & $5.68 \mathrm{~d}(7.0)$ \\
\hline $12 \mathrm{~b}-\mathrm{H}$ & 3.98 br s & 2.53 br d $(7.0)$ \\
\hline
\end{tabular}

$\delta: \operatorname{ppm}(J=\mathrm{Hz})$ in DMSO- $d_{8}$ at $400 \mathrm{MHz}$.

nected to the olefinic methine carbon of the partial structure (A).

${ }^{1} \mathrm{H}_{-}{ }^{13} \mathrm{C}$ Shift correlation spectral analysis $\left({ }^{1} \mathrm{H}-{ }^{13} \mathrm{C} \mathrm{COSY}\right)$ and long range ${ }^{1} \mathrm{H}-{ }^{13} \mathrm{C}$ COSY established a benz[a]anthraquinone structure for $\mathrm{I}$ and permitted the assignment of all the carbon signals except for those of C-6a and C12a (at $\delta 142.6$ and 143.5). Carbon signals of the quinone carbonyl in the juglone moiety appear at $\delta 189.3$ and 182.9. The signal at $\delta 189.3$ is assigned to the hydrogen-bonded quinone carbonyl due to its relative downfield chemical shift. The carbonyl carbon signal of the nonhydrogen-bonded quinone at $\delta 182.9$ (C-12) exhibits a long range coupling to the isolated methine proton at $\delta 3.98(12 \mathrm{~b}-\mathrm{H})$. Furthermore the methine proton $(12 \mathrm{~b}-\mathrm{H})$ was coupled to the quaternary carbon (C-4a), the $\alpha, \beta$-unsaturated ketone carbonyl (C-1) and two aromatic carbons at $\delta 142.6$ and 143.5 (C-6a and C-12a). One of the methylene protons at $\delta 2.60(6-\mathrm{H})$ also exhibited long range coupling to C-6a and C-12a. The above results revealed structure of $\mathbf{I}$ to be as shown in Fig. 1.

The relative configuration of $I$ was determined by a single-crystal X-ray diffraction analysis. A computer-generated perspective drawing of the final X-ray model of $I$ is shown in Fig. 2. The $\mathrm{X}$-ray analysis defined only the relative configuration, so the enantiomer shown was arbitrarily selected.
Table 2. ${ }^{13} \mathrm{C}$ NMR data of SF2315A (I) and SF2315B (II).

\begin{tabular}{lrc}
\hline Carbon & SF2315A (I) & SF2315B (II) \\
\hline C-1 & $196.2(\mathrm{~s})$ & $67.2(\mathrm{~d})$ \\
C-2 & $123.2(\mathrm{~d})$ & $122.8(\mathrm{~d})$ \\
C-3 & $161.2(\mathrm{~s})$ & $132.8(\mathrm{~s})$ \\
C-4 & $45.9(\mathrm{t})$ & $42.9(\mathrm{t})$ \\
C-4a & $69.1(\mathrm{~s})$ & $70.4(\mathrm{~s})$ \\
C-5 & $27.9(\mathrm{t})$ & $28.1(\mathrm{t})$ \\
C-6 & $20.1(\mathrm{t})$ & $17.0(\mathrm{t})$ \\
C-6a & $* 142.6(\mathrm{~s})$ & $62.2(\mathrm{~s})$ \\
C-7 & $189.3(\mathrm{~s})$ & $198.2(\mathrm{~s})$ \\
C-7a & $114.7(\mathrm{~s})$ & $112.3(\mathrm{~s})$ \\
C-8 & $160.5(\mathrm{~s})$ & $160.3(\mathrm{~s})$ \\
C-9 & $123.9(\mathrm{~d})$ & $115.6(\mathrm{~d})$ \\
C-10 & $136.8(\mathrm{~d})$ & $136.4(\mathrm{~d})$ \\
C-11 & $118.9(\mathrm{~d})$ & $117.7(\mathrm{~d})$ \\
C-11a & $132.0(\mathrm{~s})$ & $143.2(\mathrm{~s})$ \\
C-12 & $182.9(\mathrm{~s})$ & $65.8(\mathrm{~d})$ \\
C-12a & $* 143.5(\mathrm{~s})$ & $68.8(\mathrm{~s})$ \\
C-12b & $52.0(\mathrm{~d})$ & $45.4(\mathrm{~d})$ \\
C-13 & $24.0(\mathrm{q})$ & $22.7(\mathrm{q})$ \\
\hline
\end{tabular}

$\delta:$ ppm ( ) multiplicity, in DMSO- $d_{8}$ at 100 MHz.

Carbon assignment marked by * may be interchangeable. 
Fig. 1. The structures of antibiotics SF2315A (I) and B (II).

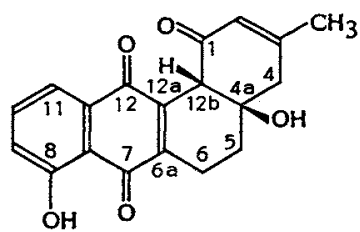

SF2315A (1)

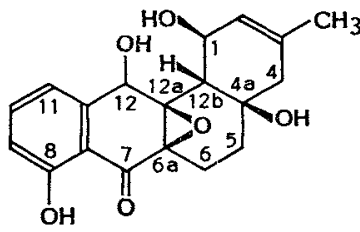

SF2315B (II)

Fig. 2. An ORTEP drawing of antibiotic SF2315A.

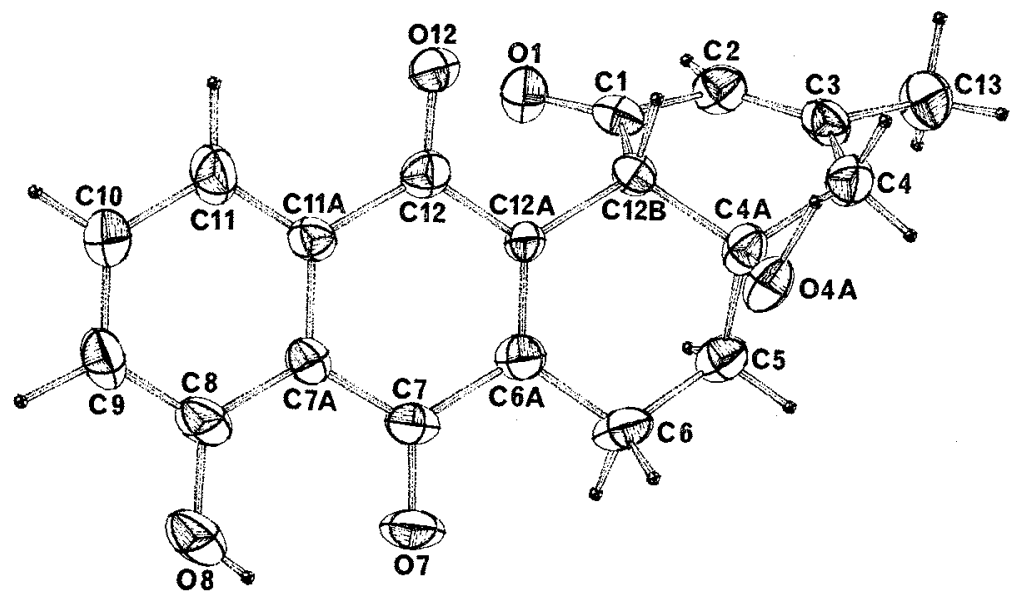

Thus, the structure of antibiotic SF2315A was determined to be either [4aR-(4a $\beta, 12 \mathrm{~b} \beta)]$ or $[4 \mathrm{a} S-(4 \mathrm{a} \alpha$,$12 \mathrm{~b} \alpha)]-4 \mathrm{a}, 5,6,12 \mathrm{~b}$-tetrahydro-4a,8-dihydroxy-3-methylbenz[a]anthracen-1,7,12(4H)-trione.

\section{Structure of SF2315B}

The molecular formula of antibiotic SF2315B (II) was determined to be $\mathrm{C}_{19} \mathrm{H}_{20} \mathrm{O}_{6}$ from the elemental analysis, HR-MS ( $\mathrm{M}^{+} \mathrm{m} / z$ calcd: 344.1258 , found: 344.1195$),{ }^{1} \mathrm{H}$ and ${ }^{13} \mathrm{C}$ NMR spectra (Tables 1 and 2).

The UV spectrum of II in methanol exhibited maxima at 267 and $339 \mathrm{~nm}$ which were shifted to 232, 268 and $376 \mathrm{~mm}$ in basic methanol. The spectrum of II showed the absorption due to a hydroxyl group $\left(3400 \mathrm{~cm}^{-1}\right)$ and a chelated carbonyl group $\left(1640 \mathrm{~cm}^{-1}\right)$ but no absorption due to an unsaturated ketone and a nonchelated quinone carbonyl group which were observed in $\mathbf{I}$. The above observations suggested the presence of an isosclerone ${ }^{3)}$ (3,4-dihydro-4,8-dihydroxy-1-(2H)naphthalenone) moiety in II. This postulate was also supported by the ${ }^{1} \mathrm{H}$ NMR spectrum of II (Table 1), which contained a phenolic hydroxyl proton at $\delta 11.33(8-\mathrm{OH})$, a hydroxyl proton at $\delta 5.68(12-\mathrm{OH})$, a methine proton at $\delta 5.29(12-\mathrm{H})$ and an $\mathrm{ABX}$ spin system of three aromatic protons at $\delta 6.87,7.18$ and $7.57(9-\mathrm{H}, 11-\mathrm{H}$ and 10-H). The other partial structures present in II were revealed as (A) $\mathrm{CHCH}(\mathrm{OH}) \mathrm{CH}=\mathrm{C}\left(\mathrm{CH}_{3}\right) \mathrm{CH}_{2}$, (B) $\mathrm{CH}_{2} \mathrm{CH}_{2}$ and (C) $\mathrm{COH}$ by spin decoupling experiments.

The ${ }^{13} \mathrm{C}$ NMR spectrum of II had 19 carbon signals, which could be attributed one ketone carbonyl, eight aromatic or olefinic carbons, three quaternary carbons, two oxymethine carbons, one methine carbon, three methylene carbons and one methyl carbon (Table 2). ${ }^{1} \mathrm{H}-{ }^{13} \mathrm{C}$ COSY and long range 
Fig. 3. An ORTEP drawing of antibiotic SF2315B.

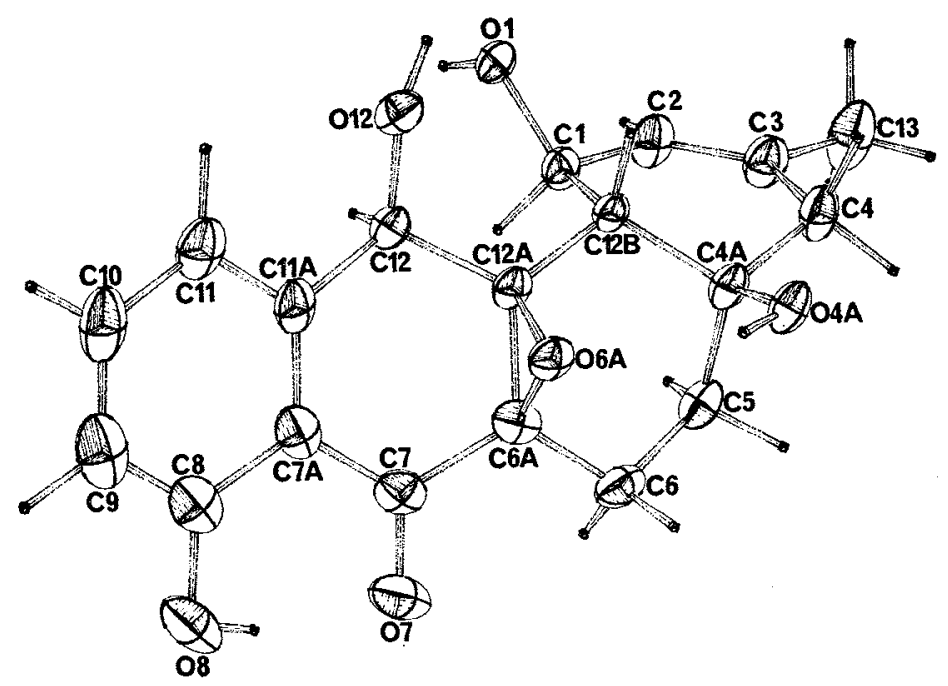

${ }^{1} \mathrm{H}-{ }^{13} \mathrm{C}$ COSY established the assignments of all carbon signals.

The methine proton at $\delta 2.53(12 \mathrm{~b}-\mathrm{H})$ was coupled to the quaternary carbon at $\delta 68.8(\mathrm{C}-12 \mathrm{a})$ and the quaternary carbon at $\delta 70.4(\mathrm{C}-4 \mathrm{a})$. The methylene proton at $\delta 2.14(4-\mathrm{H})$ was coupled to $\mathrm{C}-4 \mathrm{a}$ and the methine carbon at $\delta 45.4(\mathrm{C}-12 \mathrm{~b})$. The above results indicated that the partial structures (A) and $(\mathrm{C})$ formed a six membered ring which was attached to the $\mathrm{C}-12 \mathrm{a}$ of the isosclerone moiety. Long range couplings were observed between $\mathrm{C}-12 \mathrm{a}$ and the methylene protons $(6-\mathrm{H})$ which revealed the linkage of the partial structure (B) and the isosclerone moiety.

On the basis of the index of hydrogen deficiency of II, the remaining oxygen atom has to form an oxyran ring with the quaternary carbons of C-6a and C-12a.

By a comparison of these spectral data for II with those for I, it was concluded that the structure of II was closely related to that of $\mathbf{I}$. The $\alpha, \beta$-unsaturated ketone carbonyl carbon $(\mathrm{C}-1)$ and the non-hydrogen-bonded quinone carbonyl carbon (C-12) in I were reduced to the oxymethine carbons in II. From the above mentioned results, the structure of II was deduced to be that shown in Fig. 1.

The structure and the relative stereochemistry of II was finally determined by a single-crystal $X$-ray diffraction analysis. A computer-generated perspective drawing is shown in Fig. 3. The Xray analysis defined only the relative configuration, so the enantiomer shown was arbitrarily selected.

Thus the structure of antibiotic SF2315B was determined to be either $[1 S-(1 \beta, 4 \mathrm{a} \beta, 6 \mathrm{a} \beta, 12 \beta, 12 \mathrm{a} \beta,-$ $12 \mathrm{~b} \beta)]$ or $[1 R-(1 \alpha, 4 \mathrm{a} \alpha, 6 \mathrm{a} \alpha, 12 \alpha, 12 \mathrm{a} \alpha, 12 \mathrm{~b} \alpha)]-1,4,4 \mathrm{a}, 5,6,6 \mathrm{a}, 12 \mathrm{a}, 12 \mathrm{~b}$-octahydro-1,4a,8,12-tetrahydroxy-3methyl-6a,12a-epoxybenz[a]anthracen-7(12H)-one.

\section{Experimental}

General

MP's were determined using Yamato MP-21 apparatus in glass capillary tubes. UV spectra were recorded on a Shimadzu UV-260 spectrophotometer. IR spectra were obtained in pressed $\mathrm{KBr}$ discs using a Hitachi 260-10 IR spectrophotometer. MS spectra were measured on a Hitachi M-80B mass spectrometer. Optical rotations were measured with a Perkin-Elmer model 141 polarimeter. ${ }^{1} \mathrm{H}$ and ${ }^{13} \mathrm{C}$ NMR spectra were recorded on a JNM-GX400 spectrometer. The chemical shifts in DMSO- $d_{8}$ refer to an internal standard of TMS (0 ppm). 
Single-crystal X-Ray Diffraction Analysis of SF2315A

A crystal of approximate dimensions $0.15 \times 0.15 \times 0.4 \mathrm{~mm}$ was mounted on a Philips PW-1100 $\mathrm{X}$-ray diffractometer. All X-ray measurements were made using graphite monochromated $\mathrm{CuK} \alpha$ radiation. The lattice constants were derived from setting angles of 24 higher angle $\left(\theta=21.1^{\circ} \sim 34.3^{\circ}\right)$ reflections. Crystal data: $\mathrm{C}_{19} \mathrm{H}_{16} \mathrm{O}_{5}$ Orthorhombic, $\mathrm{P} 22_{1} 2_{1} 2_{1}, a=10.958(6), b=15.887(8), c=8.906(5) \AA$, $U=1550.4 \AA^{3}, Z=4, D_{\text {cale }}=1.389 \mathrm{gcm}^{-3}, \mu$ for $C u K \alpha$ radiation $=7.93 \mathrm{~cm}^{-1}$. Intensities were measured by a $2 \theta-\omega$ scan method with a scan speed $0.1^{\circ} / \mathrm{sec}$ in $\omega$. Backgrounds were measured at each end of the scan for half the total scan time. For weak reflections whose intensities were less than 3000 counts during the single scan, the scans were repeated once. A total of 1177 reflections in the $2 \theta$ range $6^{\circ} \sim 156^{\circ}$ was measured.

The phases of 124 strong reflections with $|E|>1.47$ were determined by direct method using MULTAN $^{4)}$. The $E$-map for the best solution yielded positions for all the non-hydrogen atoms.

In the final refinement, the non-hydrogen atoms were refined anisotropically by block-diagonal least-squares. The hydrogen atoms were included in the structure factor calculations but their parameters were not refined.

The final $\mathrm{R}$ value was 0.083 for 1177 observed reflections. In the present structure determination, no attempt has been made to assign the absolute configuration. An ORTEP ${ }^{5)}$ drawing of the molecule is shown in Fig. 2.

Single-crystal X-Ray Diffraction Analysis of SF2315B

A purified preparation of antibiotic SF2315B was recrystallized from ethanol as transparent prismatic crystals. A crystal of approximate dimensions $0.15 \times 0.15 \times 0.3 \mathrm{~mm}$ was mounted on a Philips PW-1100 X-ray diffractometer. All X-ray measurements were made using graphite monochromated $\operatorname{CuK} \alpha$ radiation. The lattice constants were derived from setting angles of 16 higher angle $\left(\theta=15.1^{\circ} \sim 25.7^{\circ}\right)$ reflections.

Crystal data: $\mathrm{C}_{19} \mathrm{H}_{20} \mathrm{O}_{8}$, Orthorhombic, space group $\mathrm{P} 2{ }_{1} 2_{1} 2_{1}, a=14.287(7), b=20.780(10), c=$ 5.645(3) $\AA, U=1675.9 \AA^{3}, Z=4, D_{\text {calo }}=1.365 \mathrm{gcm}^{-3}, \mu$ for $\mathrm{CuK} \alpha$ radiation $=8.04 \mathrm{~cm}^{-1}$.

Intensities were measured by a $2 \theta-\omega$ scan method with the scan speed $0.1 \%$ sec in $\omega$. Backgrounds were measured at each end of the scan for half the total scan time. For the weak reflections whose intensities were less than 3000 counts during the single scan, the scans were repeated once. A total of 1079 reffections in the $2 \theta$ range $6^{\circ} \sim 156^{\circ}$ was measured. The phases of 200 strong reflections with $|\mathrm{E}|>1.25$ were determined by direct methods using MULTAN ${ }^{4}$. The E-map for the best solution yielded positions for all the non-hydrogen atoms.

In the final refinement, the non-hydrogen atoms were refined anisotropically by block-diagonal least-squares. The hydrogen atoms were included in the structure factor calculations but their parameters were not refined.

The final $\mathrm{R}$ value was 0.052 for 1079 observed reflections. In the present structure determination, no attempt has been made to assign the absolute configuration. All the crystallograhic calculations were done on a IBM 4381 computer at the Meiji information system center, using the UNICS III program ${ }^{6)}$. An ORTEP ${ }^{5)}$ drawing of the molecule is shown in Fig. 3.

\section{Acknowledgment}

The authors deeply thank Dr. SHINICH Kondo for his encouragement throughout this work.

\section{References}

1) Sasaki, T.; J. Yoshida, M. Itoh, S. Gomi, T. Shomura \& M. Sezaki: New antibiotics SF2315A and B produced by an Excellospora sp. I. Taxonomy of the strain, isolation and characterization of antibiotics. J. Antibiotics 41: 835 842, 1988

2) Morton, R.A. \& W.T. Earlam: Absorption spectra in relation to quinones: 1,4-naphthoquinone, anthraquinone and their derivatives. J. Chem. Soc. Chem. Commun. 1941: 159 169, 1941

3) Morita, T. \& H. AoKI: Isosclerone, a new metabolite of Sclerotinia sclerotiorum (LiB.) De Bary. Agric. Biol. Chem. 38: 1501 1505, 1974 
4) Germain, G.; P. Main \& M. M. Woolfson: The application of phase relationships to complex structures. III. The optimum use of phase relationships. Acta Crystallogr. Sec. A 27: 368 376, 1971

5) JoHnson, G. K.: ORTEP. A Fortran Thermal Ellipsoid Plot Program for Crystal Structure Illustrations. Report ORNL-3794. Oak Ridge National Laboratory, Oak Ridge, Tennessee, U.S.A., 1965

6) SAKURAI, T. \& K. KoBAYASHI: On the universal crystallographic computation program system (5). UNICS III system. Rep. Inst. Phys. Chem. Res. 55: 69 77, 1979 